\title{
El bacilo de Eberth va a la guerra con la Royal Army
}

\author{
WALTER LEDERMANN D.
}

\section{The Eberth bacillus goes to the war with the Royal Army}

A fines del siglo pasado se vivía una conflictiva relación en Sudáfrica, entre los británicos, que habían adquirido el dominio de la región, y la población boer o afrikaner, descendientes de los antiguos colonos holandeses. Ante el continuo avance de los ingleses durante la segunda mitad del siglo, los boers se habían desplazado progresivamente a través del río Orange. Los boers así trasplantados (voortrekkers) fundaron dos estados independientes, el Transvaal en 1852 y el Estado Libre de Orange en 1854. Inglaterra anexó el Trasnvaal en 1877, desatando la Primera Guerra Boer, en la cual los voortrekkers recuperaron "casi toda" su independencia. Entre tanto, los boers que habitaban en los territorios dominados por Inglaterra se sentían segregados; a su vez, eran también segregados en Transvaal, como lógica reacción, los ciudadanos británicos que habían ingresado atraídos por el descubrimiento de oro en la región. ¿A qué seguir? Las guerras tienen confusas y absurdas razones: en 1899 estalló la Segunda (o Gran) Guerra Boer, que duró hasta 1902¹. Los Estados boer se aliaron y pusieron en armas 35.000 hombres; Gran Bretaña, que tenía 12.000 en la región, trajo otros 10.000 desde India y movilizó gente en la metrópoli hasta enterar alrededor de 50.000 para empezar el combate solamente.... y el bacilo de Eberth, muchos, muchos billones de unidades formadoras de colonias.

Para 1899 la bacteriología estaba muy avanzada. Eberth había demostrado que el Bacillus typhosus era el agente causal de la fiebre tifoidea en 1880, luego fueron descubiertos los bacilos paratíficos, la serología diagnóstica fue implementada en 1896 y el mismo año se inició la vacunación. Gran Bretaña entró a la guerra con las mismas táctica y organización empleadas 45 años antes en la Guerra de Crimea, lo cual le costó caro frente a la guerrilla boer, y con "una floja aplicación del conocimiento médico", perdiendo más vidas por la "guerrilla typhosa" que por las balas.

La mencionada Guerra de Crimea, a mediados del siglo XIX, merece ser recordada desde el punto de vista bélico sólo por una carga de caballería y, desde el punto de vista médico, por una mujer excepcional. Rusia, que luchaba contra una poderosa combinación de naciones que integraban Gran Bretaña, Francia, Cerdeña y el Imperio Otomano, sufrió en Balakava, el 25 de octubre de 1854, la famosa "Carga de la Brigada Ligera" británica, que mereciera un bello poema de Tennyson, la filmación de una épica pelí- cula norteamericana y una frase para el bronce del general francés Bosquet: C'est magnifique, mais ce n'est pas la guerre ${ }^{2}$. El aporte médico lo hizo una enfermera, Florence Nightingale, "el Ángel de Crimea" o "la dama de la lámpara", cuyas medidas higiénicas hicieron disminuir la mortandad de los hospitales de campaña en $40 \%{ }^{3}$, logro muy significativo tomando en cuenta que, entre abril de 1854 y junio de 1856, la armada inglesa en Oriente tuvo 218.952 hospitalizaciones, en $11 \%$ motivadas por heridas en batalla y en $89 \%$ por enfermedades contraídas en campaña. Los registros médicos del ejército francés son también elocuentes acerca del rol preponderante de las enfermedades durante este conflicto bélico: participaron 300.900 soldados galos, atendidos por un cuerpo de 82 médicos, muriendo por enfermedad la cuarta parte de estas tropas. Expresado de otra manera, los franceses perdieron 20.000 hombres "por fuego" y 75.000 por enfermedades, fundamentalmente entéricas (no aparece clara la separación entre tifoidea y tifus $)^{4}$.

Al iniciarse el conflicto sudafricano, Gran Bretaña mantenía un buen contingente militar en India, la perla de su Imperio: hombres acostumbrados al rigor, entrenados para sobrevivir en un clima tremendo. Allí Wright probó en 1896 una vacuna antitífica, preparada con un cultivo muerto del bacilo de Eberth, en dos heroicos oficiales médicos (no militares) del Indian Medical Service. La vacuna, preparada por el mismo Wright en la Royal Army Medical en Londres, contenía bacilos muertos por calentamiento a 60 grados C. por cinco minutos ${ }^{5}$. Se recuerda el nombre del primero, llamado Maxwell Dick ("M.D." en las publicaciones), quien fue inoculado el 31 de julio de 1896 con un veinteavo "de un tubo de bacilo tifoso muerto"6. M. D. tuvo el valor de recibir, no sólo dos dosis más, el 14 de agosto y el 5 de septiembre, sino un vigoroso booster de bacilo tifoso vivo el 25 de septiembre. Ni Dick ni el anónimo segundo voluntario hicieron tifoidea con este más bien challenger que booster, pero tuvieron tan buena respuesta serológica, que la vacunación se extendió a todo el contingente destacado en India, alcanzando una cobertura de $100 \%$ hacia 1909 . El éxito fue abrumador: en la guarnición de Peshawar, por ejemplo, de 11,3 casos por año y por mil soldados, la tifoidea había descendido a 0,6 por mil en 19137. Esta es una cifra más que excelente, considerando que hacia 1885 la morbilidad por infecciones entéricas en la armada inglesa destacada en las colonias era de 
1.374 por mil al año, con una mortalidad de 15,4 por mil efectivos ${ }^{4}$.

Ante la posibilidad de una guerra boer, la vacuna Wright se había aplicado a cerca de 100.000 voluntarios $^{8}$, pero sólo una mínima fracción de ellos formó parte del primer contingente enviado a combate. El cuerpo médico del ejército inglés hizo un gran esfuerzo y logró realizar, en medio de las hostilidades, un pequeño estudio comparativo, con un resultado que se estimó remarkable: la mortalidad por tifoidea en el grupo vacunado sería luego de 8\% (142 de 1.758 ) versus $16,6 \%$ (1.800 de 10.980) en el grupo no vacunado. Sin embargo, el hecho que 142 soldados recién vacunados fallecieran de tifoidea hizo pensar que se estaba lejos de obtener una completa inтunidad ${ }^{7}$.

La Gran Guerra Boer merece algunas reflexiones epidemiológicas. Los ingleses, como se dijo, llegaron al conflicto con las mismas prácticas militares de Crimea: su servicio de inteligencia militar y sus mapas era pobres; su caballería brillante, pero poco efectiva en terreno abrupto, por lo que debieron confiar más en su infantería; mantenían, además, un rígido sistema de castas militares, que muchas veces dificultaba su acción ${ }^{1}$. Probablemente, sólo uno que otro de los más viejos entre los 12.000 hombres que formaban la guarnición local había participado en 1879 en la guerra contra los zulúes, adquiriendo experiencia acerca de la lucha en territorio africano, aunque en esa desigual "guerra" Cetewayo, sobrino del famoso Chaka, les propinara un tremendo e inesperado revés en Isandhlwana9.

Vale la pena detenerse un momento en esta catástrofe. Los guías "expertos" aseguraban que los zulúes no pelearían, pues era noche de plenilunio y nunca lo hacían en esa circunstancia. Atardecía; los ingleses, en la llanura, se confiaron más de la cuenta, por su parte, los indunas o jefes zulúes no lograban tranquilizar a sus hombres; éstos, sentados en sus escudos, ennegrecían en semicírculo las lomas circundantes. Finalmente, sin que nadie diera la orden, miles de guerreros bajaron corriendo hacia el campamento inglés, cortaron sus líneas y obtuvieron una resonante victoria ${ }^{10}$. Isandhlwana "engrosó en 530 muertos la lista de fallecidos en esta guerra de escaramuzas y emboscadas, perdiendo en total la armada inglesa 838 efectivos por heridas y 329 por enfermedad"4. Podría especularse argumentando que justamente por esta característica de guerrilla, con acciones rápidas, el bacilo de Eberth "no sedimentó": no hubo grandes aglomeraciones de tropas ni sitios prolongados que favorecieran brotes entéricos. Gran Bretaña puso fin al conflicto con una gran victoria en Ulundi, después de la cual la Reina Victoria invitó al monarca Cetewayo a conocer Inglaterra, sabia manera de convencer al vencido de la imposibilidad de triunfar ante una potencia europea.

Los boers estaban acostumbrados a la vida salvaje del veldt, la llanura africana; eran grandes jinetes, hábiles con el rifle, individualistas, resueltos y esforzados; contaban con formidables convoyes de carretas, que les permitían independizarse del ferrocarril y moverse a campo traviesa; por último, tenían un excelente cuerpo de artilleros con instrucción germánica. Solían parapetarse en altura, desde donde podían cargar o huir con ventaja; mientras se movieron rápido tuvieron poca tifoidea, pero ésta los diezmó cuando, derrotados, fueron internados en campos de refugiados. Los ingleses debieron enfrentar largas marchas: Roberts, quien llegó a mandar 38.000 hombres, con los cuales tuvo que marchar a través de territorio hostil, de modo que difícilmente tuvieron tiempo de cavar pozos negros y las infecciones entéricas han debido cebarse en ellos. Los boers, por su parte, fueron los primeros en implementar, en la defensa de Magersfontein, extensas trincheras con alambre de púas, que tan características llegarían a ser el la Primera Guerra Mundial. Con el tiempo estas defensas generarían sus propias enfermedades, como la fiebre de las trincheras. En estas siniestras zanjas anidó el bacilo de Eberth y los boers empezaron a sufrirlo de verdad.

La triste experiencia de los miles que murieron no a mano de los boers sino del bacilo typhoso, hizo que Gran Bretaña empezara a inmunizar regularmente a sus militares "de ultramar" y que, al iniciarse la Primera Guerra Mundial tuviera cierta experiencia con esta práctica.

Francia llegaba aún en mejor pie, lo que no debe sorprender, pues contaba con una bacteriología "de punta" para la época, disponiendo de mejores laboratorios, mejores métodos diagnósticos, mejores bacteriólogos à l'Institute Pasteur y una superior información epidemiológica acumulada. En la guerra franco-prusiana, en 1870, el bacilo de Eberth había ayudado al ejército francés al infectar a 74.205 de los 815.000 soldados que había reunido Bismarck, matando a 8.904 de ellos, pérdida equiparable a la sufrida por el ejército prusiano en la decisiva batalla de Sedán ${ }^{11}$. Esto motivó una fuerte preocupación por la higiene militar, poniendo énfasis en el abastecimiento de agua, la disposición de excretas y la inhumación de cadáveres. Se establecieron hasta tiempos de marcha, pues se pensaba que "el surmenage, en su sentido más amplio, prepara admirablemente el medio interior para la invasión y crecimiento de los gérmenes". También se creía que, aparte del contagio fecal-oral, la tifoidea podía transmitirse por vía aéreas, disponiéndose normas para la construcción de alojamientos aireados ${ }^{13}$. Por decreto del 31 de octubre de 1892 se establecían claras directrices para la construcción de los cuarteles de campaña y de las letrinas (alejadas de las fuentes de agua), así como para la sepultura de los muertos. En esta inhumación era "deseable la presencia de un médico", tanto para constatar la muerte, como para vigilar las condiciones higiénicas del sitio elegido : "un suelo poroso, permeable, seco, en declive, alejado de la fuente de agua más inmediata, evitando arena y arcilla, practicándose la sepultura a dos metros de profundidad"14.

Estados Unidos había comenzado sus intentos por inmunizar la tropa en 1904, con un desafortunado experimento. James Carroll, famoso por su lucha contra la fiebre amarilla; Edward Vedder, quien más tarde demostrara la etiología del beri-beri; y Harry 
Gilchrist, luego célebre por la campaña antitifus en Polonia, probaron una vacuna antitífica oral. Esta consistía en $30 \mathrm{ml}$ de un cultivo de seis días de bacilos tifosos, muertos por calentamiento a 56 grados $\mathrm{C}$ durante una hora. Ingirieron la vacuna los tres investigadores y diez voluntarios. De los trece, doce nunca habían tenido tifoidea: luego de ingerir la vacuna enfermaron siete y otros tres "tuvieron una enfermedad febril". La experiencia, de puro desastrosa, no salió a la luz hasta $1959^{15}$. En 1908 el US Surgeon General F.F. Russell, del Army Medical School, tomó el toro por las astas y decidió vacunar de una vez por todas a las tropas estadounidenses, para lo cual se fue a los laboratorios británicos y alemanes, a ver cómo era la fabricación, desarrollando a su regreso una contundente vacuna: bacilo tifoso cultivado en agar, muerto por calor, células enteras, preservación con tricresol. Un grupo selecto de oficiales del Medical Reserve Corps of the Army analizó todos los antecedentes, recomendando la vacunación "voluntaria" a partir de 1909: el cien por ciento se vacunó, tan enérgica fue la recomendación... Hacia 1911 ya había una sólida experiencia con 20.000 vacunados, sin que se registrara una sola reacción adversa seria, de modo que se decretó la vacunación de todo el personal menor de 45 años ${ }^{17}$.

Del ejército alemán sólo se sabe, por Pfeiffer, que la mortalidad por tifoidea durante la guerra varió entre 12 y $20 \%$ entre los no-inoculados, contra 2 a $3 \%$ entre los inoculados ${ }^{17}$. Cabe suponer que buen número de soldados estaban vacunados, ya que el 28 de noviembre de 1902 había Robert Koch enviado una célebre carta a la Kaiser Wilhelm Akademie encareciendo la vacunación antitífica, desatando con ella una intensa campaña de inmunización ${ }^{18}$.

Al comenzar la guerra, Inglaterra envió a Francia un contingente militar denominado la British Expeditionary Force (BEF). Sólo 30\% de los hombres que componían la BEF estaba vacunado con una dosis de 1.000 millones del "bacilo tifoso", pero "órdenes son órdenes" y más en tiempo de guerra, de manera que a fines de 1914 ya los inoculados alcanzaban al $80 \%$ y al $90 \%$ en 1915 . En ese momento se decidió agregar un nuevo sufrimiento a la tropa, al adicionar a la vacuna anti-tífica (T) los bacilos paratifoso A y paratifoso B (TAB). Hablo de agregar un sufrimiento, pues una vacuna de ese tipo, con
Tabla 1. Esquema de vacunación la de BEF a partir del $1^{\circ}$ Enero de 1916

Composición por ml de la vacuna del Royal Arm Medical College, Millbank
B. typhosus
B. paratyphosus $A$
1.000 millones
B. paratyphosus $B$
750 millones
750 millones

\begin{tabular}{llll}
\hline Calendario: & Día & 0 & $0,5 \mathrm{ml}$ \\
& Día & 10 & $1,0 \mathrm{ml}$ \\
\hline Cobertura: & 50 millones de dosis de $1 \mathrm{ml}$ \\
\hline $\begin{array}{l}\text { Accidentes reportados "into several millions of men }= \\
\text { not a single case" }\end{array}$
\end{tabular}

Fuente: Sir William Leishman: Official History of the War, Medical Services, Pathology, 1923 (19).

bacterias enteras, poseedoras de una potente endotoxina, muertas por calor-fenol, debiera producir intensas reacciones locales y generales. Parece que no fue así o los soldados eran muy rudos, dada la ausencia de accidentes señalada en la Tabla 1, que reseña el programa de inmunización.

Los resultados obtenidos con la vacuna $\mathrm{T}$ sola habían sido estimado favorables, aunque hoy merecerían discusión. Así, en los dos primeros años de campaña (1914-1915) hubo 545 casos de tifoidea entre los no vacunados, con una letalidad de $20,3 \%$, versus 426 entre los vacunados, con una letalidad de $6,84 \%$ entre los que recibieron una dosis de $\mathrm{T}$ sola y del $8,05 \%$ entre los que recibieron dos. Introducida la vacuna TAB en 1916 y vacunados rápidamente several millions (en 1915 ya iban 614.715 individuos inmunizados) hasta el 31 de diciembre de 1918, tanto de la BEF como del resto de las tropas británicas, los resultados eran ampliamente satisfactorios para las autoridades militares, comparados con los obtenidos en la Gran Guerra Boer (Tabla 2)

Una curiosa redistribución de la población susceptible a la fiebre tifoidea se vivió después de la guerra, gracias a la vacunación de las tropas. Tanto en Francia, Alemania e incluso en EE.UU., hubo una alteración entre la distribución de los casos por edades y por sexos. Hacia 1921 se consignaba que en Francia la tifoidea había casi desaparecido entre los

Tabla 2. Incidencia y mortalidad relativas por fiebres entéricas entre las tropas británicas enroladas en la Gran Guerra Boer y la Primera Guerra Mundial

\begin{tabular}{lll}
\hline Tropas movilizadas por año & 208.226 & 2.000 .000 \\
Incidencia anual por mil & 105 & 2,35 \\
Mortalidad por mil & 14,6 & 0,139 \\
Total de casos en la guerra & 57.684 & 20.139 \\
Total de fallecidos & 8.022 & 1.191 \\
\hline
\end{tabular}

Fuente: Sir William Leishman. Official History of the War, Medical Services, Pathology, 1922. 
varones de 20 a 45 años de edad y que, ya a partir de 1918, se había invertido de distribución por sexo, haciéndose las fiebres entéricas más frecuentes entre las mujeres ${ }^{20}$. En la epidemia de Hanover en 1927 , Hahn reporta 2.423 casos de tifoidea, señalando que, mientras que en el grupo de 10 a 30 años la distribución por sexos era similar, en cambio en el grupo de 31 a 50 años eran mucho más afectadas las mujeres, porque muchos varones habían sido vacunados durante la guerra ${ }^{21}$.

¿Quién ganó, finalmente, en la Gran Guerra Boer? Teóricamente, Gran Bretaña; en realidad, nadie, como en todas las guerras. Gran Bretaña movilizó en total la friolera de 450.000 hombres para este conflicto en un remoto territorio, de los cuales fallecieron alrededor de 22.000, más de 14.000 de ellos por enfermedad. De éstos, el entonces llamado Bacillus typhosus se llevó 8.022. En cuanto a los boers, se calcula que ocuparon más de 60.000 , con una pérdida estimada en 24.000 vidas, 20.000 de ellas perdidas en los campos de refugiados, seguramente en gran parte a causa del mismo bacilo ${ }^{1}$. El único triunfo fue el de la vacuna antitífica, que permitió reducir las pérdidas de los ingleses no sólo en el próximo conflicto bélico, sino entre sus tropas acantonadas en India.

En cuanto a la Primera Guerra Mundial, los resultados fueron también desastrosos para los humanos. Ya en 1916, al término de la primera fase del conflicto, se estimaba que habían fallecido ocho millones de hombres en total, muchos de ellos por enfermedad $^{22}$. Todos los países europeos involucrados terminaron empobrecidos y devastados. Los progresos médicos obtenidos como subproducto de tanta destrucción no bastan para compensarla.

Hoy en día, los desafíos médicos que impone la movilización de un gran número de tropas a territorios lejanos y con pobre saneamiento siguen siendo formidables, e incluyen proporcionar alimentación segura, inmunización contra enfermedades exóticas, adecuada disposición de excretas, aparte de completos hospitales de campaña y de personal de salud muy bien entrenado. Sin embargo, con todos los adelantos médicos, durante la reciente Guerra del Golfo más de la mitad de las tropas estadounidenses, acampadas en Saudi Arabia, presentó al menos un episodio de diarrea y $20 \%$ requirió ser relevado temporalmente por esta causa, aunque ninguno falleció víctima de Salmonella, Shigella u otro malvado enteropatógeno ${ }^{23}$. Al momento de escribir estas líneas, leemos en El Mercurio el comentario de un reciente estudio de Robert Haley, de la Universidad de Texas, publicado en Radiology de Junio 2000, donde se señala una pérdida neuronal de hasta $20 \%$, evidenciada con resonancia magnética, en ex combatientes de esta guerra, a causa de gases tóxicos que habrían empleado los iraquíes ${ }^{24}$. ¿Será la hora de añorar al ingenuo bacilo de Eberth?

\section{Bibliografía}

1.- Kruger R. Boer war. Collier's Encyclopedie. Crowell Collier \& McMillan Inc, USA 1967; 4: 300-5.

2.- Howard H N. Crimean war. Collier's Encyclopedie. Crowell Collier \& McMillan Inc, USA 1967; 7: 4412.

3.- Seymer L R. Nightingale, Florence. Collier's Encyclopedie. Crowell Collier and McMillan Inc, USA 1967; 17: $548-9$.

4.- Viry C H. Principes d'Hygiene militaire. L.Bataille et Cie., Editeurs, Ancien Maison Delahaye, Place de l'Ecole de Médecine, Paris 1896; pp 7-27.

5.- Wright A E. Typhoid vaccine. Lancet 1896; ii: 80712.

6.- Wright A E, Semple D. Note on B. typhosus vaccine. Br Med J 1897; I: 256.

7.- Harvey D. Bacillus typhosus. In: A System of Bacteriology in relation to Medicine. His Majesty Stationery Office, London 1929; IV: 50-9.

8.- Benenson A S. Immunization and military medicine. Rev Infect Dis 1984; 6 (1): 1-12.

9.- Butler J. Natal. Collier's Encyclopedie. Crowell Collier \& McMillan, USA 1967; 17: 149-51.

10.- Haggard R. Zulu. III: Finished. Acme Agency, Buenos Aires 1952; pp 216-9.

11.- Bonner A. Battle of Sedan. Collier's Encyclopedie. Crowell Collier \& McMillan, USA 1967; 20: 563.

12.- Kelsh L. Traité des maladies épidémiques. Octave Doin, Editeur, París 1894; p. 450.

13.- Morache G. Traité d'Hygiene Militaire. Librarie JB Baillière et fils, Paris 1890; pp 760-74.

14.- Rochard V J. Encyclopedie d'Hygiene. Librarie JB Baillière et fils, Paris 1890; IV: 94-7.

15.- Tiggert W D. The initial effort to immunize American soldier volunteers with typhoid vaccine. Milit Med 1959; 124: 342-9.

16.- Russell F F. Anti typhoid vaccination. Am J Med Sci 1913; 146: 803-33.

17.- Pfeiffer R F J. Erfarungen in Weltkriege. Handb Arztl 1922; 7: 327-31.

18.- Bulloch W. Bacillus typhosus. History. In: A System of Bacteriology in relation to medicine. His Majesty Stationery Office, London 1929; IV: 15-7.

19.- Leishman W B. Tables from Official History of War. RAMC (J1) 1921; 37: i.

20.- Chauffard A, Archard S. Fievre typhoide. Resumé 1921. Bull Acad Méd, Paris 1921; 85: 84-89; 182; 445.

21.- Hahn M. Typhus-bacillus, Hannover 1926. Med klinik 1927; 23: 1009-15.

22.- Kraus M. World War I. Collier's Encyclopedie. Crowell Collier \& McMillan, USA 1967; 23 : 593-605.

23.- Hyams K C, August M P, Bourgeois M P et al. Diarrheal disease during Operation Desert Shield. N Engl J Med 1991; 325 (20): 1423-8.

24.- Estudio de la Universidad de Texas: Veteranos del Golfo muestran daño cerebral. El Mercurio 27-05-2000; A: 7. 